\title{
BMJ Open Healthcare use among preschool children attending GP-led urgent care centres: a descriptive, observational study
}

\author{
S Gnani, ${ }^{1}$ S Morton, ${ }^{1} \mathrm{~F}$ Ramzan, ${ }^{1}$ M Davison, ${ }^{2}$ T Ladbrooke, ${ }^{3}$ A Majeed, ${ }^{1}$ \\ S Saxena ${ }^{1}$
}

To cite: Gnani S, Morton S, Ramzan $\mathrm{F}$, et al. Healthcare use among preschool children attending GP-led urgent care centres: a descriptive, observational study. BMJ Open 2016;6: e010672. doi:10.1136/ bmjopen-2015-010672

- Prepublication history for this paper is available online. To view these files please visit the journal online (http://dx.doi.org/10.1136/ bmjopen-2015-010672).

Received 25 November 2015 Revised 20 March 2016 Accepted 18 April 2016
CrossMark

\footnotetext{
${ }^{1}$ Department of Primary Care and Public Health, Imperial College London, London, UK ${ }^{2}$ North End Medical Centre, London, UK

${ }^{3}$ London Central and West Unscheduled Care Collaborative, London, UK
}

Correspondence to Dr S Gnani;

s.gnani@imperial.ac.uk

\section{ABSTRACT}

Objective: Urgent care centres' (UCCs) hours were developed with the aim of reducing inappropriate emergency department (ED) attendances in England. We aimed to examine the presenting complaint and outcomes of care in 2 general practitioner (GP)-led UCCs with extended opening times.

Design: Retrospective observational epidemiological study using routinely collected data.

Setting: 2 GP-led UCCs in London, colocated with a hospital ED.

Participants: All children aged under 5 years, attending 2 GP-led UCCs over a 3-year period.

Outcomes: Outcomes of care for the children including: primary diagnosis; registration status with a GP; destination following review within the UCC; and any medication prescribed. Comparison between GPled UCC visit rates and routine general practices was also made.

Results: $3 \%$ ( $n=7747 / 282947$ ) of all attenders at the GP-led UCCs were children aged under 5 years. The most common reason for attendance was a respiratory illness (27\%), followed by infectious illness (17\%). $18 \%(n=1428)$ were either upper respiratory tract infections or viral infections. The majority $(91 \%)$ of children attending were registered with a GP, and over two-thirds of attendances were 'out of hours'. Overall $79 \%$ were seen and discharged home. Preschool children were more likely to attend their GP (47.0 per 100) than a GP-led UCC (9.4 per 100; $95 \%$ Cl 8.9 to 10.0 ).

Conclusions: Two-thirds of preschool children attending GP-led UCCs do so out of hours, despite the majority being registered with a GP. The case mix is comparable with those presenting to an ED setting, with the majority managed exclusively by the GPs in the UCC before discharge home. Further work is required to understand the benefits of a GP-led urgent system in influencing future use of services especially emergency care.

\section{INTRODUCTION}

Pressures on emergency departments (EDs) continue to rise in many developed countries, placing health systems such as England's

\section{Strengths and limitations of this study}

- This study provides an insight into the reasons children under the age of 5 years attend the general practitioner (GP)-led urgent care centre (UCC), an area that has not previously been studied.

- The study incorporates data from over a 3-year period from two GP-led UCCs with good data completeness.

- No follow-up data following treatment in the GP-led UCC was available for the children to see whether any of them later required hospital admission.

- This study only includes data from within central London and may not reflect other UCC settings with different populations.

National Health Service (NHS) under financial strain. Nearly half the NHS budget is spent on acute and emergency care, and children are among the highest users. Around $10 \%$ of those attending EDs are preschool children aged under 5 years. ${ }^{1}{ }^{2}$ One-third visited an ED at least once in 2011/2012 (959 502/3 304 990). ${ }^{3}$ This number has risen by $40 \%$ in the past decade, and is associated with an increase in emergency hospital admissions. ${ }^{4} \mathrm{Up}$ to $40 \%$ of $\mathrm{ED}$ attendances are believed to be 'inappropriate' particularly among young children, ${ }^{2}$ and it is estimated that $10 \%$ of infants (aged $<1$ year) attending the ED have no underlying medical problem. ${ }^{5}$

Parents' first choice is their regular general practitioner (GP) when their child is unwell, but they choose to visit EDs if they believe their child's condition is serious. ${ }^{6-8}$ Children living in deprived areas are more likely to attend EDs, ${ }^{9}$ particularly out of hours and where access to primary care is poor. ${ }^{3} 10$

Urgent care centres (UCCs) were first introduced in England in 1999 with the aim of reducing the number of inappropriate ED 
attendances. ${ }^{11}$ From this, various models have developed, including GP-led UCCs colocated with EDs, which provide access to GPs outside of 'normal working hours'. This UCC model is the current recommendation by the Royal College of Paediatrics and Child Health, alongside the Royal College of Physicians and Royal College of Surgeons. $^{12}$

The majority of adults who attend GP-led UCCs are registered with GPs and are thought to attend due to convenience; typically, they present with acute minor illnesses and it is known that the numbers attending continue to rise. ${ }^{13}{ }^{14}$ However, little is known about the reasons preschool children attend these GP-led UCCs colocated in the $\mathrm{ED}$, what treatment they receive, and whether they go on to be admitted to hospital or not, despite them accounting for such a high percentage of ED attendances. Our aim was, therefore, to examine the main reasons for children aged $<5$ years attending two GP-led UCCs in central London and establish the outcomes of care following their attendance. We also aimed to compare the number of attendances to a GP-led UCC to those seen in general practice.

\section{METHODS}

Setting

The Hammersmith UCC opened in April 2009 and Fulham UCC in September 2009, and are colocated with the emergency unit and department at Hammersmith and Charing Cross Hospitals, respectively. ${ }^{15}$ Both are in the London Borough of Hammersmith and Fulham, which has a population of $\sim 182500 .^{16}$ Preschool children (aged $<5$ years) make up $6.5 \%$ of the population. ${ }^{17}$ The London Borough of Hammersmith and Fulham is ranked in the top $20 \%$ nationally for socioeconomic deprivation. $^{18}$ The Hammersmith UCG is open from 08:00 to 22:00, and Fulham UCG is open 24 hours a day.

On arrival at the GP-led UCCs, patients are registered at reception and are then triaged by an experienced GP who allocates the patient to the most appropriate clinical 'stream'. The streams comprise of one of the following categories: 'minor illness'; 'minor injury'; 'GP priority'; 'ED'; 'expected special patient'; and 'see and treat' (figure 1). At the UCCs, all preschool children are streamed as 'GP priority', or are seen in the 'see and treat' stream by a GP; they are not seen by an emergency nurse practitioner. Parents cannot access ED care without being first seen by a GP at the UCC, as is the case for any adult patient. If 'inpatient' paediatric care is required then this initiates specialist referral to one of two neighbouring hospitals with paediatric facilities; St Mary's Hospital or Chelsea \& Westminster Hospital. There is also a Children's Ambulatory Care unit available at Hammersmith hospital, which is open between 09:00 and 17:00, Monday to Friday.

No ethical approval was sought for this study, in line with National Research Ethics Service Guidance, as routinely available data were used and the project was considered a service evaluation. ${ }^{19}$

\section{Data sources and extraction}

Patients' data are entered into the UCCs administrative and clinical information system-Adastra. ${ }^{20}$ Adastra is one of the main computer systems used to manage episodes of patient care in walk-in centres, UCCs, minor injuries units, front-ends to $\mathrm{A} \& \mathrm{E}$, and call centres for GP out of hours. Adastra uses the Read clinical codes V.2. Read codes are a coded thesaurus of clinical terms used in the NHS, mainly primary care, since 1985, which include diagnosis and process of care terms. ${ }^{21}$

All clinical information on reasons for attendance was recorded by either the GP streamer or the GP who provided treatment to the attending child; the Read codes were related either to a diagnosis or presenting symptom. Data collection is ongoing. Data items include: demographics (date of birth, sex, ethnicity, postcode); and GP registration; and clinical information ('stream' allocation, diagnosis, investigation, prescribing and treatment); and outcomes of care (discharge or onward referral) data.

We extracted data for UCC attendances among preschool children from 1 October 2009 to 31 December 2012 (39 months). Attendances were considered as 'out of hours' if the arrival time was outside 08:00 to 18:30, and Monday to Friday. We excluded all children $<5$ years of age brought in by ambulance, as they bypassed the UCCs, attending the ED directly.

\section{Statistical analysis}

We analysed data by 1-year age bands for all attendances, as reasons for attendances and illness patterns differ widely, for example, between toddler and infants in their first year.

We described the baseline characteristics of preschool children attending the GP-led UCCs, including registration status with a GP, time of attendance and outcomes of care (discharge or referral). Ethnicity data were missing for $9 \%$ of attendances.

We examined the main reason for attendance recorded by the GP, which was identified by the primary Read code. We excluded attendances due to missing Read codes; $24 \%(n=1871)$ had a missing code, or a 'process of care' code such as a wound dressing recorded by the GP. Missing diagnostic Read codes occurred when children were: seen in the 'see and treat' stream; redirected by reception to another service; diverted by the GP streamer to ED; and when parents chose not to wait.

QResearch database has pseudo-anonymised data for over 18 million patients, covering 1000 UK practices, from patients currently registered as well as historical records. We used QResearch GP consultation data from 1995 to 2009 (latest available) collected at 602 general practices. We undertook linear regression to calculate the expected national consultation rate in 2011 for children aged under 5 years, using 2011 England census data as the denominator. We calculated the UCC attendance rate, by dividing the number of attendances observed among Hammersmith and Fulham residents in 


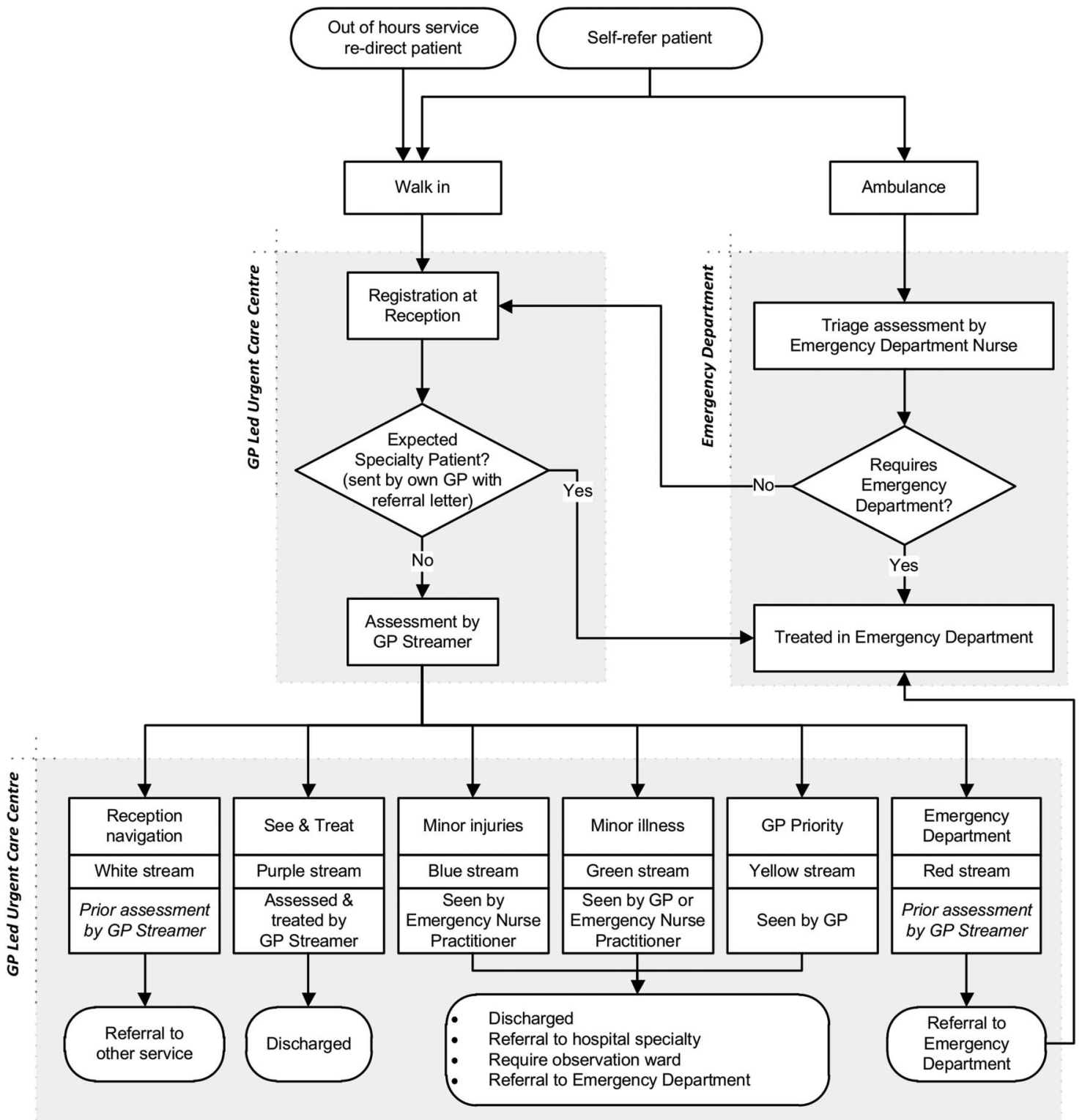

Figure 1 Patient pathway across the integrated general practitioner-led model of care (reproduced from Gnani et al.) ${ }^{15}$

this age group, by the population for Hammersmith and Fulham (2011 census figure). ${ }^{22}$

We examined prescribing by British National Formulary (BNF) Chapter Headings, Group Level 1, by age band. ${ }^{23}$ We used t tests and $\chi^{2}$ tests to compare proportions and test for statistical significance $(p<0.05)$. All analyses were performed using Stata V.11 (STATA Data analysis and statistical software (01/07/2013). http:// www.stata.com/).

\section{RESULTS}

During the 39-month study period, nearly $3 \%(\mathrm{n}=7747 /$ 282 947) of total attendances at the GP-led UCCs were among preschool children (8.4 per 1000 attendances per year). There were 72.8 per 1000 attendances per year, with $3 \%(95 \%$ CI $2.5 \%$ to $3.5 \%)$ of children reattending within 7 days of their initial attendance. There were $46 \% \quad(n=3558)$ of attendances at Fulham UCC. There were slight differences in mean age of attendance between Fulham (1.8 years; $\mathrm{SD} \pm 1.4$ ) and Hammersmith UCCs (1.6 years; $\mathrm{SD} \pm 1.4$ ). Under half of all children were resident in the London Borough of Hammersmith and Fulham (47\%) or in North West London (42\%; table 1).

Although $91 \%$ of children attending the UCCs were registered with a GP, $69 \%(\mathrm{n}=5350)$ of attendances took place out of hours when general practices were closed; $40 \%$ of children who attended were discharged home without any follow-up, with $65 \% \quad(n=1999)$ of these attending out of hours. We found a further $76 \%$ of children, who were discharged home with advice to seek routine GP follow-up (39\%), attended outside normal GP hours; $8 \%$ of preschool children attendances required immediate referral to the ED, while $11 \%$ were seen by UCC GP, who sought a specialist or paediatric opinion. 
Table 1 Sociodemographic profile, GP registration status, time of attendance and discharge outcome among preschool children attending the UCCs

\begin{tabular}{|c|c|c|c|c|c|c|}
\hline $\begin{array}{l}\text { Age (years) } \\
\mathrm{N}\end{array}$ & $\begin{array}{l}<1 \\
1953\end{array}$ & $\begin{array}{l}1 \text { to }<2 \\
2015\end{array}$ & $\begin{array}{l}2 \text { to }<3 \\
1439 \\
\%\end{array}$ & $\begin{array}{l}3 \text { to }<4 \\
1255\end{array}$ & $\begin{array}{l}4 \text { to }<5 \\
1085\end{array}$ & $\begin{array}{l}\text { Total } \\
7747\end{array}$ \\
\hline \multicolumn{7}{|l|}{ Sex } \\
\hline Girls & 46 & 47 & 45 & 47 & 47 & 46 \\
\hline \multicolumn{7}{|l|}{ Ethnicity } \\
\hline White & 50 & 52 & 46 & 47 & 42 & 48 \\
\hline Black or Black British & 11 & 13 & 14 & 13 & 13 & 13 \\
\hline Asian or Asian British & 8 & 7 & 9 & 10 & 11 & 9 \\
\hline Chinese or other ethnic groups & 14 & 14 & 15 & 13 & 16 & 14 \\
\hline Mixed & 7 & 6 & 7 & 8 & 9 & 7 \\
\hline Not stated & 9 & 8 & 8 & 9 & 9 & 9 \\
\hline \multicolumn{7}{|l|}{ Area of residence } \\
\hline Hammersmith and Fulham Borough & 42 & 46 & 47 & 47 & 53 & 47 \\
\hline North West London excluding Hammersmith and Fulham & 45 & 42 & 41 & 41 & 36 & 42 \\
\hline Outside North West London & 12 & 11 & 11 & 11 & 10 & 11 \\
\hline Non-UK & 0.3 & 0.2 & 0.1 & 0.1 & 0.2 & 0.2 \\
\hline \multicolumn{7}{|l|}{ GP registration status } \\
\hline Registered & 88 & 92 & 92 & 94 & 93 & 91 \\
\hline \multicolumn{7}{|l|}{ Time of attendance } \\
\hline During GP core contract hours (08:00-18:30) & 30 & 30 & 29 & 33 & 34 & 31 \\
\hline Outside GP core contract hours & 70 & 70 & 71 & 67 & 66 & 69 \\
\hline \multicolumn{7}{|l|}{ Discharge outcome } \\
\hline Discharged home & 39 & 39 & 40 & 41 & 42 & 40 \\
\hline Discharged home with GP follow-up & 39 & 39 & 38 & 39 & 39 & 39 \\
\hline Referred to hospital specialist & 12 & 11 & 11 & 9 & 9 & 11 \\
\hline Referred to emergency department & 7 & 8 & 9 & 9 & 6 & 8 \\
\hline Did not wait & 2 & 1 & 1 & 1 & 1 & 1 \\
\hline Discharged home with community service or UCC follow-up & 1 & 1 & 1 & 2 & 2 & 1 \\
\hline
\end{tabular}

Using national QResearch data, we found that preschool children were more likely to attend their GP (4.7 per $100,95 \%$ CI 46.9 to 47.1 ) compared with the UCCs (9.4 per $100 ; 95 \%$ CI 8.9 to 10.0 ).

Table 2 summarises the commonest reasons for children attending the UCCs. Children attended most with the diagnosis of a 'respiratory system disease' (27\%); mainly an upper respiratory tract infection $(n=1004)$. This was followed by the diagnosis under the chapter heading of an 'infectious or parasitic disease' (17\%) that includes non-specific viral infections and viral gastroenteritis, followed by 'injury and poisoning' (16\%), for instance, head injury ( $\mathrm{n}=306)$.

Table 3 shows that $59 \%(4537 / 7747)$ of UCC attendances were connected with preschool children receiving at least one medication (BNF heading). The most commonly prescribed medication among children were for infections $(18 \%)$, with the majority of these being antibacterial drugs $(n=1372)$. This was followed by medication under the 'Central Nervous System', which almost entirely consisted of analgesics (eg, paracetamol) $(\mathrm{n}=766)$, followed by medications for 'Skin conditions' $(7 \%)$, such as emollient and barrier preparations $(\mathrm{n}=181)$, and then the 'Respiratory system' $(7 \%)$, for example bronchodilator medication $(n=247)$.

\section{DISCUSSION}

\section{Main findings}

Only $3 \%$ of all attendances to the GP-led UCCs were among preschool children over a 3-year period, with nearly a quarter of them being repeat attenders. Although the large majority of children attending were registered with a GP, over two-thirds attended out of hours. The most common reason for attending the GP-led UCG was for a respiratory disease, mainly an upper respiratory tract infection. The most commonly prescribed medications were for infections. Only one in five preschool children who attended required a referral to a paediatrician or an emergency doctor. In comparison with QResearch data, it was calculated that preschool children were more likely to attend their GP than the GP-led UCC.

\section{Findings compared with previous studies}

Around $10 \%$ of those attending the ED in 2013-2014 were aged $<5$ years, significantly more than the $3 \%$ 
Table 2 Main presenting diagnosis by Read code chapter among preschool children attending the UCC

\begin{tabular}{|c|c|c|c|c|c|c|c|}
\hline Rank & $\begin{array}{l}\text { Age (years) } \\
\mathbf{N} \\
\text { Diagnosis by Read code chapter }\end{array}$ & $\begin{array}{l}<1 \\
1232\end{array}$ & $\begin{array}{l}1 \text { to }<2 \\
1421\end{array}$ & $\begin{array}{l}2 \text { to }<3 \\
997 \\
\%\end{array}$ & $\begin{array}{l}3 \text { to }<4 \\
866\end{array}$ & $\begin{array}{l}4 \text { to }<5 \\
777\end{array}$ & $\begin{array}{l}\text { Total } \\
5293\end{array}$ \\
\hline 1 & Respiratory system diseases & 24 & 26 & 27 & 31 & 29 & 27 \\
\hline 2 & Infectious or parasitic diseases & 20 & 21 & 15 & 14 & 11 & 17 \\
\hline 3 & Injury and poisoning & 9 & 16 & 18 & 18 & 22 & 16 \\
\hline 4 & (D) Symptoms, signs, ill-defined conditions & 16 & 10 & 9 & 9 & 9 & 11 \\
\hline 5 & Nervous system. sense organ disease & 9 & 11 & 12 & 12 & 10 & 11 \\
\hline 6 & Skin or subcutaneous tissue disease & 10 & 7 & 6 & 6 & 7 & 7 \\
\hline 7 & Digestive system diseases & 4 & 2 & 3 & 2 & 1 & 3 \\
\hline 8 & Musculoskeletal or connective tissue & 1 & 2 & 3 & 2 & 3 & 2 \\
\hline 9 & Unspecified conditions (community terms) & 3 & 2 & 1 & 2 & 2 & 2 \\
\hline 10 & Genitourinary system diseases & 1 & 1 & 3 & 2 & 3 & 2 \\
\hline 11 & Additional Read chapter codes (where total <80) & 3 & 3 & 3 & 2 & 3 & 3 \\
\hline
\end{tabular}

attending the GP-led UCCs in our study. ${ }^{1}$ This is also a significant difference between our study and one study that found one in three children aged $<15$ years attended the ED between 2011 and 2012. ${ }^{10}$ This difference may be accounted for by decisions taken by parents, possibly in consultation with primary care providers, because of a lack of inpatient paediatric services at both the Hammersmith and Fulham sites. GPs (and similarly parents) may be aware not to send their children to these sites if they thought that the child might require hospital admission. However, it may also be due to a lack of usage and awareness of the UCCs by parents, and perhaps greater education is required to promote the use of the UCC rather than the ED, especially as $<20 \%$ required onward referral.

The finding that $>80 \%$ of attendances to the GP-led UCC are dealt with and do not require onward referral may suggest that the UCC is able to adequately manage most of the attendances in preschool children and potentially decrease the number of admissions. This is similar to a study in a paediatric ED in Italy which showed that $70 \%$ of patients were discharged. ${ }^{24}$ It also reflects what was seen in the overall population, including adults, attending the same GP-led UCCs. ${ }^{25}$ It could be extrapolated that if they do not require admission then a large number of these attendances are 'inappropriate'; $27 \%$ of attendances were either for an upper respiratory tract infection or a viral infection.

One UK study that encompassed the same time period as our study found that inappropriate attendances peak in childhood within an ED setting, and that $28 \%$ of attendances in the age group $0-15$ years were inappropriate. ${ }^{2}$ Another study among children aged $0-18$ years in Canada, judged only $34 \%$ of attendances to the paediatric ED to be appropriate, and $36 \%$ in an Irish study suggesting this observation is not just within the UK setting. ${ }^{26}{ }^{27}$ While all these studies examine children with a wider age range than in our study, we know that one study found that $\sim 10 \%$ of infants (aged $<1$ year) attending an ED had no underlying medical problem. ${ }^{5}$ Hence, our results echo findings from other studies whereby parents often believe a child's condition to be more serious than it actually is. ${ }^{67}$

One Canadian study found that $82 \%$ of parents overestimated the seriousness of their child's condition, and yet $58 \%$ did not contact their GP before coming to the

Table 3 Percentage of UCC attendances among preschool children prescribed at least one medication

\begin{tabular}{|c|c|c|c|c|c|c|}
\hline $\begin{array}{l}\text { Age (years) } \\
\mathrm{N} \\
\text { Percentage prescribed medication }\end{array}$ & $\begin{array}{l}<1 \\
1953 \\
51\end{array}$ & $\begin{array}{l}1 \text { to }<2 \\
2015 \\
58\end{array}$ & $\begin{array}{l}2 \text { to }<3 \\
1439 \\
60\end{array}$ & $\begin{array}{l}3 \text { to }<4 \\
1255 \\
65\end{array}$ & $\begin{array}{l}4 \text { to }<5 \\
1085 \\
65\end{array}$ & $\begin{array}{l}\text { Total } \\
7747 \\
59\end{array}$ \\
\hline \multicolumn{7}{|c|}{ Percentage prescribed medication breakdown by British National Formulary chapter headings } \\
\hline Infections & 10 & 17 & 21 & 23 & 24 & 18 \\
\hline Central nervous system & 8 & 10 & 10 & 12 & 12 & 10 \\
\hline Skin & 10 & 6 & 5 & 5 & 6 & 7 \\
\hline Respiratory system & 6 & 7 & 7 & 9 & 6 & 7 \\
\hline Musculoskeletal and joint diseases & 3 & 7 & 7 & 7 & 9 & 6 \\
\hline Eye & 5 & 4 & 3 & 3 & 2 & 4 \\
\hline Nutrition and blood & 3 & 3 & 3 & 3 & 1 & 3 \\
\hline Ear, nose and oropharynx & 4 & 2 & 2 & 2 & 2 & 3 \\
\hline Gastrointestinal system & 2 & 1 & 1 & 1 & 1 & 1 \\
\hline
\end{tabular}


ED. ${ }^{28}$ This may, to some extent, explain why, despite 92\% of the preschool children attending the UCCs having a registered GP, parents chose to take them to 'hospital' as they were very concerned, similar to findings in other studies of EDs. ${ }^{6}$ It may also explain to some extent why there was such a high percentage $(70 \%)$ of out of hours attendances, as parents were too concerned to wait for their GP to be open. Other reasons could include a lack of knowledge in accessing other out of hours care services and/or convenience. This figure is higher than the national average of $56 \%$ for out of hours attendances, which is seen within the ED for paediatrics. ${ }^{10}$ This may partly be explained by the fact that $10 \%$ of children attending the UCCs were not registered with a GP. Although there is no national data on the proportion of children registered with a GP, we know that $98 \%$ of the UK population is registered. A possible explanation for this finding may relate to local factors such as international migrants, who may not be aware of the health system and, therefore, have not registered with a local GP practice. ${ }^{29}$

Respiratory system disease was found to be the most common reason for attending the UCCs, although this is likely to overlap with the second most common reason of 'infectious and parasitic diseases' that is mainly a nonspecific viral infection. This is similar to findings in other ED studies, where percentages for respiratory disease attendances range from $25 \%$ to $36 \% .^{6}{ }^{24}$ However, it differs to what was found for adolescents attending a UCC, where musculoskeletal conditions were the most common. ${ }^{30}$ As a result, the most commonly prescribed medications were antibiotics for infection, and analgesics, especially paracetamol, all of which are routinely prescribed in the community and do not require emergency attendance. The prescription rate for infections of $18 \%$ in our study compares with a study reporting $47 \%$ of preschool children receiving a prescription for a viral infection. ${ }^{31}$ Although rates have fallen over time, they still remain high. ${ }^{32}$

Overall, by using QResearch data, we found that preschool children were more likely to attend general practice than an UCC. This may be due to routine attendances to general practice, such as for immunisations, and goes some way to explaining the fivefold difference. The main reasons for attendance at general practices are similar to urgent care; mainly with an upper respiratory tract infection. ${ }^{33} 34$ This suggests that parents are taking preschool children to both general practice and UCCs, although our study cannot determine if they receive advice from their GP before attendance, a finding that has been noted in other studies. ${ }^{6}$

\section{Strengths and limitations of the study}

This study provides an insight into reasons for attending two GP-led UCCs with preschool children, an area that has not previously been examined. Over 3 years of data were examined for two sites with good data completeness, so as to ensure there were no significant changes in attendance rates compared to the initial opening of the UCC. The completeness of the data allows us to understand more about the initial presenting complaint and medication prescribed, something that is often not available within an ED setting. It also enabled us to examine the time trends and mitigate the effects of seasonal variation in patterns of ED attendance.

A key limitation was the inability to follow-up patients who were discharged home to establish whether they required hospital admission later. Also, this study was performed in central London, where there is a young and mobile population, and therefore, it may not fully reflect other UCC settings with different populations.

In under a quarter of attendances, there were missing data on the presenting complaint; the field was not mandatory for clinicians to complete. This occurred when children were redirected by reception to another service, were streamed as a see and treat and, therefore, discharged home or referred to the ED or a paediatrician. This is unlikely to have affected the ranking of conditions that children present with.

\section{Implications for policy}

We found that the majority of preschool children presenting to a GP-led UCC could be managed by the GP without requiring admission to hospital. However, the $3 \%$ attendance rate for preschool children is significantly less than what is seen nationally within the ED. Interestingly, for those that did attend, over two-thirds of them presented out of hours despite being registered with a GP, suggesting that parents often felt they could not wait or could not gain access to their own GP.

It appears that the presentations to the UCC are similar to those presenting to ED, and the majority can be managed by a GP resulting in discharge home. It may be that parents view the GP-led UCC as a substitute for attending the ED as they want to access immediate care. However, what is important to determine in future studies is whether attending GP-led services result in parents becoming more confident in caring for their children, without needing medical advice, and whether this leads to a long-term reduction in service use. Although if parents continue to attend EDs and UCCs frequently without changing their health seeking behaviour, then the benefits are harder to ascertain.

\section{CONCLUSION}

Overall, there was a lower rate of attendance of children under 5 years of age to the GP-led UCC in comparison with the averages, nationally, for EDs. Preschool children were more likely to attend the GP-led UCCs out of hours than during the day, mainly with conditions that were managed by GPs within the UCC before discharge home. More research is required to understand why parents chose to visit the UCC despite the fact that the majority of children were registered with a GP, but it is 
likely that availability is an important factor. As it appears that the GP-led UCC has a very similar caseload variety to the $\mathrm{ED}$, it suggests that parents are using GP-led UCCs in a similar way as EDs.

Acknowledgements The authors thank the staff working for Partnership for Health in setting up the services; and staff at Hammersmith and Charing Cross Hospital EDs. Partnership for Health is a consortium of London Central and West Unscheduled Care Collaborative, Imperial College London Healthcare Trust (Acute Hospital) and Central London Community Health Services. The Department of Primary Care and Public Health at Imperial College London is grateful for support from the North West London NIHR Collaboration for Leadership in Applied Health Research \& Care (CLAHRC), the Imperial NIHR Biomedical Research Centre, and the Imperial Centre for Patient Safety and Service Quality (CPSSQ).

Contributors SG initiated the study, drafted and revised the manuscript. SM drafted and revised the manuscript. FR collected data and undertook the analysis. MD, TL, AM and SS all helped to revise the manuscript. All authors read and approved the final manuscript.

Funding This article presents independent research commissioned by the National Institute for Health Research (NIHR) under the Collaborations for Leadership in Applied Health Research and Care (CLAHRC) programme for North West London. The views expressed in this publication are those of the authors and not necessarily those of the NHS, the NIHR or the Department of Health.

Competing interests SG, FR, AM and SS are employed by Imperial College London, which received funding to help evaluate the new model of care.

Provenance and peer review Not commissioned; externally peer reviewed.

Data sharing statement No additional data are available.

Open Access This is an Open Access article distributed in accordance with the Creative Commons Attribution Non Commercial (CC BY-NC 4.0) license, which permits others to distribute, remix, adapt, build upon this work noncommercially, and license their derivative works on different terms, provided the original work is properly cited and the use is non-commercial. See: http:// creativecommons.org/licenses/by-nc/4.0/

\section{REFERENCES}

1. Centre HaSCl. Hospital Episode Statistics: Accident and Emergency Attendances in England-2013-14. 2015. http://www.hscic.gov.uk/ catalogue/PUB16728/acci-emer-atte-eng-2013-14-rep.pdf (accessed 6 Jun 2016).

2. McHale $\mathrm{P}$, Wood S, Hughes $\mathrm{K}$, et al. Who uses emergency departments inappropriately and when-a national cross-sectional study using a monitoring data system. BMC Med 2013;11:258.

3. Cecil E, Bottle A, Cowling T, et al. Primary care access, emergency department visits, and unplanned short hospitalizations in the UK. Pediatrics 2016;137:1-9.

4. Saxena S, Bottle A, Gilbert R, et al. Increasing short-stay unplanned hospital admissions among children in England; Time Trends Analysis '97-'06. PLOS ONE 2009;4:e7484.

5. Heys M, Kwong HM, Reed J, et al. What do we really know about infants who attend Accident and Emergency departments? Perspect Public Health 2014;134:93-100.

6. Williams A, O'Rourke P, Keogh S. Making choices: why parents present to the emergency department for non-urgent care. Arch Dis Child 2009;94:817-20.

7. Woolfenden S, Ritchie J, Hanson R, et al. Parental use of a paediatric emergency department as an ambulatory care service. Aust N Z J Public Health 2000;24:204-6.

8. Maguire $\mathrm{S}$, Ranmal R, Komulainen $\mathrm{S}$, et al. Which urgent care services do febrile children use and why? Arch Dis Child 2011;96:810-16.

9. Beattie TF, Gorman DR, Walker JJ. The association between deprivation levels, attendance rate and triage category of children attending a children's accident and emergency department. Emerg Med J 2001;18:110-11.

10. Cecil E, Bottle A, Sharland M, et al. Impact of UK primary care policy reforms on short-stay unplanned hospital admissions for children with primary care-sensitive conditions. Ann Fam Med 2015;13:214-20.

11. Health Do. Up to £30M to develop $20 \mathrm{NHS}$ fast access walk-in centres 1999 (cited 9 Sep 2015). http://www.gov-news.org/gov/uk/ news/up_to_30m_to_develop_20_nhs_fast_access_walk/37123.htm

12. Medicine TPARCoE. Time to Act-Urgent Care and A\&E: the patient perspective. 2015. http://www.patients-association.org.uk/wpcontent/uploads/2015/06/rcem-pa-report-time-to-act.pdf (accessed 6 Jun 2016).

13. Amiel C, Williams B, Ramzan F, et al. Reasons for attending an urban urgent care centre with minor illness: a questionnaire study. Emerg Med J 2014;31:e71-5.

14. Cowling TE, Ramzan F, Majeed A, et al. Attendances at Charing Cross and Hammersmith Hospitals' urgent care centres, 2009-12. BMJ 2013;347:f7035.

15. Gnani S, Ramzan F, Ladbrooke T, et al. Evaluation of a general practitioner-led urgent care centre in an urban setting: description of service model and plan of analysis. JRSM Short Rep 2013;4:2042533313486263.

16. London Borough of Hammersmith \& Fulham. Hammersmith and Fulham 2011 Census Data Report - First Release. 2011. https:// www.lbhf.gov.uk/sites/default/files/section_attachments/ hammersmith_and_fulham_2011_census_data_report_-_first_ release.pdf (accessed 6 Jun 2016).

17. GLA-Intelligence. 2011 Census first results: London boroughs' populations by age by sex: GLA-Intelligence. 2012. http://data. london.gov.uk/datastorefiles/documents/2011-census-first-results.pdf

18. London Borough of Hammersmith \& Fulham: population profile: London Borough of Hammersmith \& Fulham. 2006. http://www.lbhf. gov.uk/Images/3.\%20FINAL\%20proof\%20-\%20Population_ tcm21-56259.pdf

19. NHS-HRA. NHS Health Research Authority: National Research Ethics Service (9 September 2013). http://www.nres.nhs.uk/ applications/is-your-project-research/

20. Advanced-Healthcare. Adastra Clinical Patient Management System (8 July 2013). http://www.advancedcomputersoftware.com/ahc/ products/adastra-patient-management-system.php

21. HSCIC. Read Codes 2013 (14 March 2016). http://systems.hscic gov.uk/data/uktc/readcodes

22. Hippisley-Cox J, Vinogradova Y. NHS Information Centre Trends in Consultation rates in General Practice 1995 to 2008: Analysis of the QResearch database: 2008/09 Report \& Tables September 2009 (8 July 2013). http://www.hscic.gov.uk/catalogue/PUB01077

23. BNF. British National Formulary 2013 (19 Augest 2013). http://www. bnf.org/bnf/index.htm

24. Giacalone T, Vanelli M, Zinelli $C$, et al. One year experience at the Emergency Unit of the Children's Hospital of Parma. Acta Biomed 2003;74:34-7.

25. Cowling TE, Ramzan F, Ladbrooke T, et al. Referral outcomes of attendances at general practitioner led urgent care centres in London, England: retrospective analysis of hospital administrative data. Emerg Med J 2016;33:200-7.

26. Oberlander TF, Pless IB, Dougherty GE. Advice seeking and appropriate use of a paediatric emergency department. Am J Dis Child 1993;147:863-7.

27. Mallon B, Cullen A, Keenan $\mathrm{P}$, et al. A profile of attenders at the A \& E department of the Children's Hospital, Temple Street, Dublin. Ir Med J 1997;90:266-7.

28. Truman CD, Reutter L. Care-giving and care-seeking behaviours of parents who take their children to an emergency department for non-urgent care. Can J Public Health 2002;93:41-6.

29. Hargreaves S, Friedland JS, Gothard P, et al. Impact on and use of health services by international migrants: questionnaire survey of inner city London A\&E attenders. BMC Health Serv Res 2006;6:153.

30. Gnani S, McDonald H, Islam S, et al. Patterns of healthcare use among adolescents attending an urban general practitioner-led urgent care centre. Emerg Med J 2014;31:630-6.

31. Wang EEL, Einarson TR, Kellner JD, et al. Antibiotic Prescribing for Canadian Preschool Children: evidence of Overprescribing for Viral Respiratory Infections. Clin Infect Dis 1999;29:155-60.

32. Thompson PL, Spyridis N, Sharland M, et al. Changes in clinical indications for community antibiotic prescribing for children in the UK from 1996 to 2006: will the new NICE prescribing guidance on upper respiratory tract infections just be ignored? Arch Dis Child 2009;94:337-40.

33. Royal College of General PMcCormick A, Fleming D, Charlton J, Office of Population C, et al. Morbidity statistics from general practice: fourth national study 1991-1992. London: H.M.S.O., 1995.

34. Sands R, Shanmugavadivel D, Stephenson T, et al. Medical problems presenting to paediatric emergency departments: 10 years on. Emerg Med J 2012;29:379-82. 